\title{
A Novel Design of Miniaturaized Patch Antenna Using Different Substrates for S-Band and C-Band Applications
}

\author{
Saad Hassan Kiani \\ Electrical Engineering Department \\ Iqra National University \\ Peshawar, Pakistan \\ Khalid Mahmood \\ Electrical Engineering Department \\ Iqra National University \\ Peshawar, Pakistan
}

\author{
Sharyar Shafeeq \\ Electrical Engineering Department \\ Iqra National University \\ Peshawar, Pakistan \\ Mehre Munir \\ Electrical Engineering Department \\ Iqra National University \\ Peshawar, Pakistan
}

\author{
Khalil Muhammad Khan \\ Electrical Engineering Department \\ Iqra National University \\ Peshawar, Pakistan
}

\begin{abstract}
In advance communication technology, patch antennas are widely exploit due to their inexpensive and light weighted structure. This paper presents a novel design of miniaturized multiband patch antenna using different substrates frequently used in patch antennas. Various substrates such as Teflon, Roger 5880, Bakelite and Air are in use to achieve better gain and directivity. The proposed miniaturized multiband patch antenna contains 2 substrates where one substrate is FR4 (fixed and lossy) and the other substrates are changed to observe gain, directivity and return loss. Coaxial probe serving mode is presented in this paper. This serving mode is a contacting arrangement for patch, in which the outer conductor is linked to ground plane and the inner conductor of the coaxial connector spreads through dielectric and is bonded to the radiating patch. The proposed antenna can be used for various S-band and Cband applications.
\end{abstract}

Keywords-substrates; microstrip; return loss; directivity; miniaturized; Impdence bandwidth

\section{INTRODUCTION}

Micro strip antennas are widely used in communication devices for various applications such as radars, satellites and mobile phones etc. They are low cost, small structured and easily fabricated. Considerable amount of approaches have been develop for reducing the size of antenna but the central concern with the reduced area of an antenna is its minor gain. Some methods here are discussed below.

With the use of synthetic magnetic conductor area of antenna was reduced but with the result of lowered gain [1]. As gain was significantly improved as compared to magnetic conductor using split ring resonators but the reverse outcome was that reduce size was approximately equal to $10 \%$ [2]. The size reduction was achieved above $20 \%$ by way of Koch Fractal shape but with few repetitions gain starts diminishing [3].

In this paper we have analyzed a fractal pi shaped dual substrate patch antenna where one substrate is FR4 (fixed and lossy) and second is a variable one as a double substrate antenna shows good return loss [4]. Stage of substrate material is an considerable job in designing a patch antenna, as the restrictions regarding micro strip antenna such as negligible gain, poor efficiency and directivity can be mitigated by deciding on proper substrate materials, because performance factors of patch antenna like bandwidth, gain ,radiation pattern are linked up to permittivity of substrate material .[5][6].

To the best of our knowledge, no literature review on miniaturized double substrate selection is available so we are proposing a novel design of miniaturized patch antenna substrate selection for S-Band and C-Band applications.

This paper is organized as follows:

Section I deals with introductions, section II deals with antenna design and methodology whereas section III deals with results and discussion. Concluding remarks are given in section IV.

\section{ANTENNA DESIGN}

The designing of antenna is done stage by stage in a convenient way. The basic shape is shown in figure $1(a$ and $b$ ) [5-6]. 


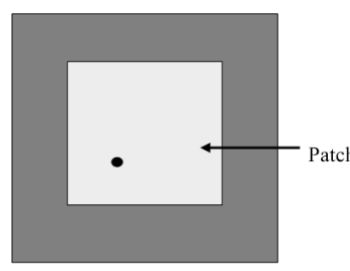

(a).

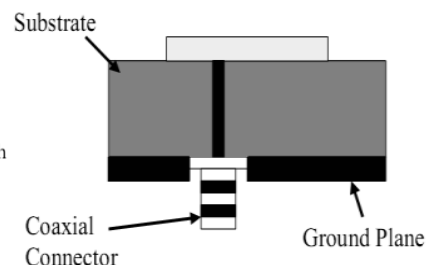

(b)
Fig. 1. (a) Top view of Micro strip patch antenna (b) Side view of patch antenna (Coaxial Cable Feed)

\section{A. Substrate Selectivity}

Parameters of patch antenna like bandwidth, radiation efficiency are linked up with substrate material used for patch so setting up substrate material is prime assignment in designing patch. Thickness of substrate significantly impacts upon parameters.

According to Coulomb's la w:

$$
E=\frac{q 1 q 2}{4 \Pi \varepsilon r r^{2}}
$$

Where $\mathrm{q} 1$ and $\mathrm{q} 2$ are the charge bodies and $\boldsymbol{\varepsilon} \boldsymbol{r}$ is the permittivity of free space and $r$ is the distance.

Electric field (E) is inversely proportional to the relative permittivity $\varepsilon r$ by increasing or decreasing relative permittivity of the various substrates change in electric field can be observed [4].The substrates used in this paper have the following dielectric constants.

TABLE I. DIFFERENT TYPES OF SUBSTRATES

\begin{tabular}{|l|l|}
\hline Substrate & Dielectric Constant \\
\hline RO5880 & 2.2 \\
\hline Air & 1.00 \\
\hline Bakelite & 4.78 \\
\hline Teflon & 2.1 \\
\hline
\end{tabular}

\section{B. Width of the Patch}

With the help of following equation, width of the patch is calculated. [4].

$$
W=\frac{c}{2 f_{0} \sqrt{\frac{(\varepsilon r+1)}{2}}}
$$

Where $\mathrm{c}=3 \times 10^{8} \mathrm{~m} / \mathrm{s}$.

\section{$f_{0}=$ Resonant Frequency}

$\varepsilon r$ is the permittivity of a substrate.

\section{Length of the Patch}

With the help of following equation, length of the patch is calculated [4].

Where

$$
L=L(e f f)-2 \Delta L
$$

$$
L(\text { eff })=\frac{c}{2 f_{0} \sqrt{E(r e f f)}}
$$

And

$$
\varepsilon_{(r e f f)}=\frac{\varepsilon r+1}{2}+\frac{\varepsilon r-1}{4}\left(1+\frac{12 h}{W}\right)^{-1 / 2}
$$

By calculating the length and width of the patch and ground, in this paper a $4 \mathrm{GHz}$ antenna is designed with coaxial feeding technique. After miniaturizing and reducing its size up to $79.12 \%$.This was achieved by using combination of Ushaped and L-shaped slots on the ground plane and pi-shaped slot on the double fractal patch of antenna with shorting pin between patch and ground [7] As a result antenna produced multiband response with a high gain and sufficient impedance bandwidth for each band [9]. We have considered thickness of the first and second substrate constant $(2 \mathrm{~mm})$ but we have changed permittivity of second substrate one by one by changing various material like, RogerRT5880, Bakelite, and Teflon and Air.

For these substrates relative permittivity is $\boldsymbol{\varepsilon} \mathbf{r}<5$.

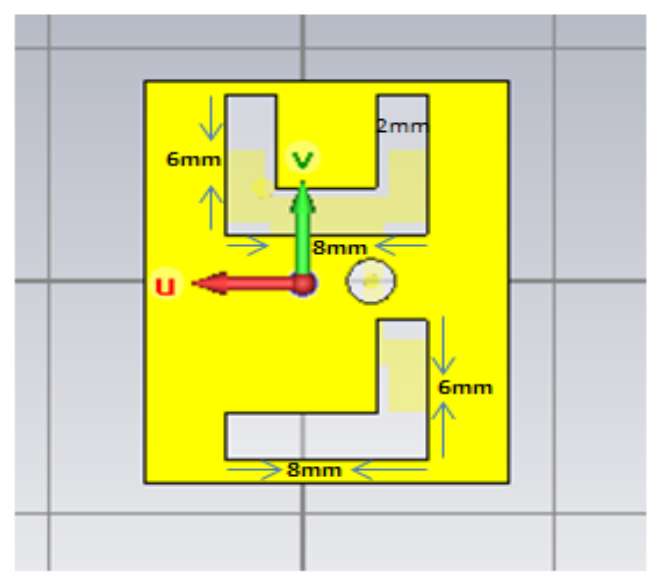

Fig. 2. Back view of Dual Fractal Patched Pi Antenna

TABLE II. DIMENSIONS OF PI SHAPED ANTENNA

\begin{tabular}{|l|l|}
\hline Parameters & Values in MM \\
\hline Length of Patch, LP & 16.95 \\
\hline Width of Patch, WG & 22.47 \\
\hline Length of Ground, LP & 28.95 \\
\hline Width of Ground, WP & 34.47 \\
\hline Slot Length, SL & 5.00 \\
\hline Slot Width, SW & 2.00 \\
\hline Pi Slot Length, PL & 4.00 \\
\hline Pi Slot Width, PW & 1.00 \\
\hline Height of Patch & 0.035 \\
\hline Height of Ground, HG & 0.8 \\
\hline Height of Substrate, HS & 2.00 \\
\hline $\begin{array}{l}\text { Horizontal U and L Slot } \\
\text { Length, HUL\&HLL }\end{array}$ & 8.00 \\
\hline $\begin{array}{l}\text { Horizontal U and L Slot } \\
\text { Width, HUW \&HLW }\end{array}$ & 2.00 \\
\hline $\begin{array}{l}\text { Vertical U and L Slot Length, } \\
\text { VUL\&VLL }\end{array}$ & 8.00 \\
\hline $\begin{array}{l}\text { Vertical U and L Slot Width, } \\
\text { VUW \&VLL }\end{array}$ & 2.00 \\
\hline
\end{tabular}




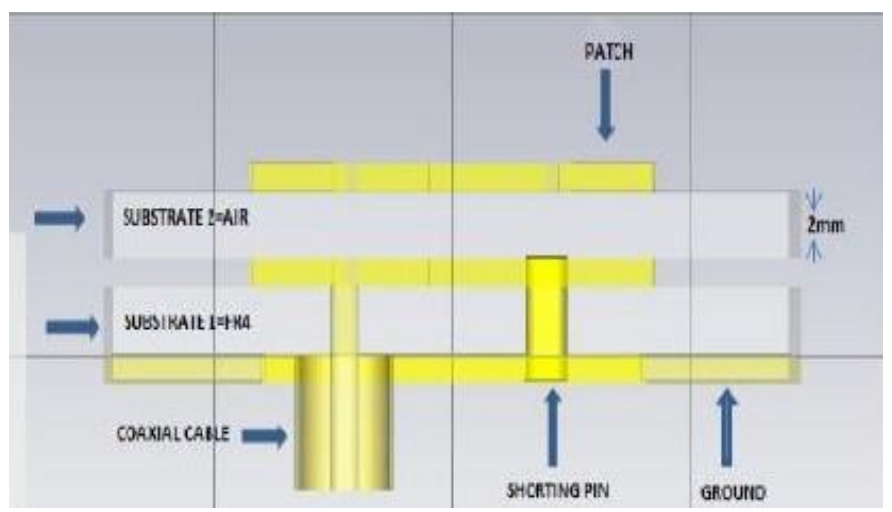

Fig. 3. Front View of Dual Fractal Patched Pi Antenna

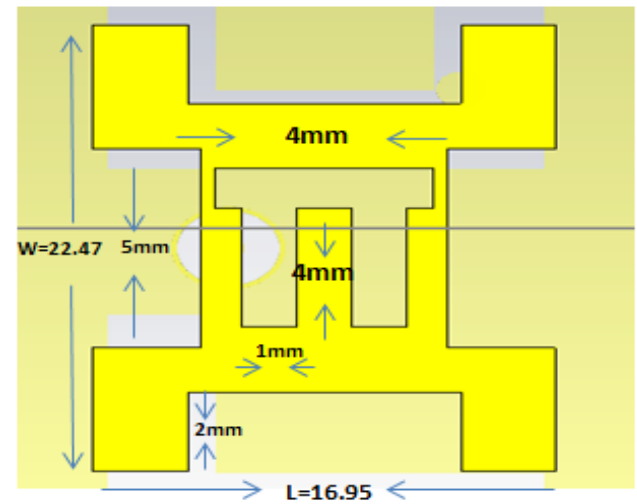

Fig. 4. Bottom View of Dual Fractal Patched Pi Antenna

The ground plane is shown in Fig II or in other terms back view of antenna. Approximately $35 \mathrm{~mm}$ and $29 \mathrm{~mm}$ are antenna width and length dimensions. $8 \mathrm{~mm} \mathrm{U}$-shape and $2 \mathrm{~mm} \mathrm{~L}$-shape holes on ground plane reduced antenna size up to quite satisfactory level. In Fig III we clearly see the overall structure of proposed patch comprising of 2 substrates where lower substrate is FR4 and upper substrate is Air and feeding coaxial probe with shortening pin connecting 2 patches. AIR has a dielectric constant of 1.00 and its thickness is taken to be $2 \mathrm{~mm}$.

Current circulation on patch of antenna is shown on Fig IV. As marked from figure, it is clear that on ends of Pi-shape slot, current concentration is supplementary as compared to rest of the patch. Introducing slots increases current distribution path, increasing electrical length and resulting in resonating frequencies shifting downward direction hence revealing several band response. As compared to traditional antenna with familiarized resonance frequency, the overall surface of antenna is reduced to excessive level.

\section{Substrate Varying}

In this section, we have used second substrate of fractal pi shape antenna and observed the gain and directivity. The First substrate to replace air is RO5880 having permittivity of 2.2.
After R05880 substrate was changed from R05880 to Bakelite having permittivity of 4.78.similarly Bakelite substrate was changed from Bakelite to Teflon having permittivity of 2.1. Various changes were seen in gain and directivity as well as return loss.

\section{RESULTS AND DISSCUSSIONS}

Satisfactory results were achieved as individual factors like radiation pattern, gain, and return loss were examined for several regularities of interest. The obtained results achieved are discussed below.

A. Air

With Air substrate, antenna showed very good results as shown in table III, by showing multi-level response at different resonant frequencies.

TABLE III. AIR SUBSTRATES RESUlTS

\begin{tabular}{|l|l|l|l|}
\hline $\begin{array}{l}\text { Resonant } \\
\text { Frequency }\end{array}$ & Return Loss & Gain & Directivity \\
\hline 2.603 & $-31.74 \mathrm{~dB}$ & $3.08 \mathrm{~dB}$ & $4.32 \mathrm{dBi}$ \\
\hline 3.119 & $-26.84 \mathrm{~dB}$ & $4.03 \mathrm{~dB}$ & $5.25 \mathrm{dBi}$ \\
\hline 3.5 & $-15.91 \mathrm{~dB}$ & 2.26 & $4.2 \mathrm{dBi}$ \\
\hline 4.21 & $-18.945 \mathrm{~dB}$ & $5.47 \mathrm{~dB}$ & $6.71 \mathrm{dBi}$ \\
\hline 6.16 & $-12.89 \mathrm{~dB}$ & $0.145 \mathrm{~dB}$ & $3.72 \mathrm{dBi}$ \\
\hline
\end{tabular}

The minimum return loss occurred at resonant frequency of $3.00 \mathrm{GHz}$ which was $-31.74 \mathrm{~dB}$ having gain of $3.08 \mathrm{~dB}$ and directivity of $4.32 \mathrm{dBi}$.

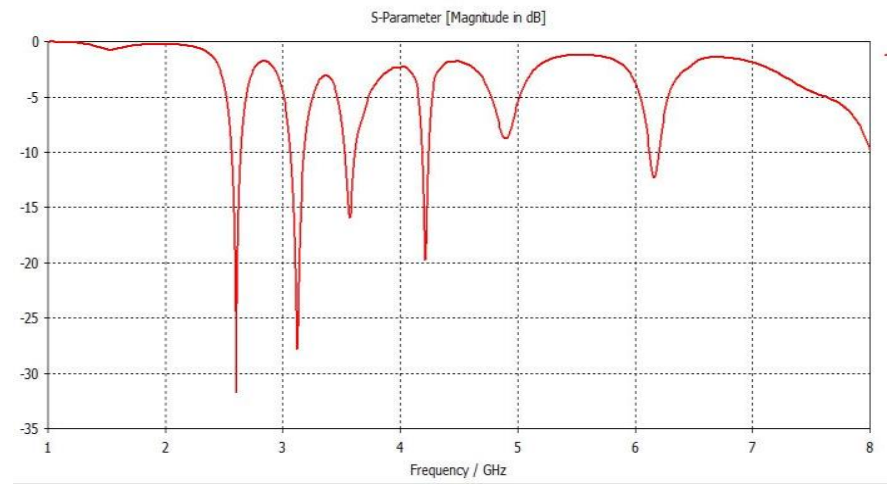

Fig. 5. Return Loss of Air

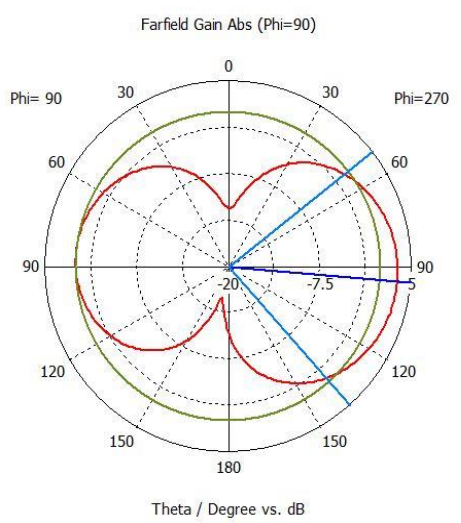

— farfield $(f=2.603)[2]$

Frequency $=2.603$

Main lobe magnitude $=3.08 \mathrm{~dB}$ Main lobe direction $=95.0 \mathrm{deg}$. Angular width $(3 \mathrm{~dB})=86.6 \mathrm{deg}$. Side lobe level $=-2.3 \mathrm{~dB}$

Fig. 6. 1D plot of Gain at Resonant Frequency of $2.603 \mathrm{GHz}$ 


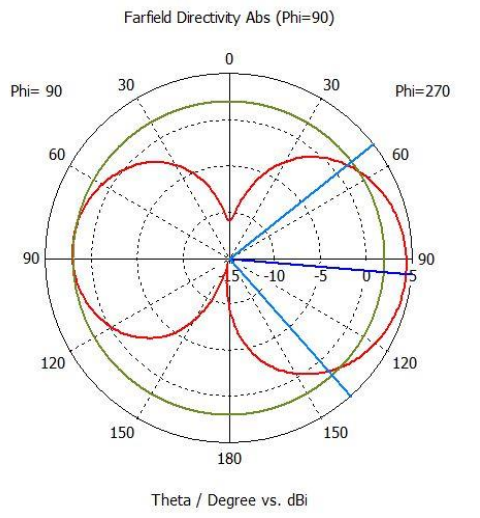
Frequency $=2.603$
Main lobe magnitude $=4.32 \mathrm{~dB}$ Main lobe direction $=95.0 \mathrm{deg}$. Angular width $(3 \mathrm{~dB})=86.6 \mathrm{deg}$. Side lobe level $=-2.3 \mathrm{~dB}$

Fig. 7. 1D plot of Directivity at Resonant Frequency of $3.00 \mathrm{GHz}$

In $2.603 \mathrm{GHz}$ the level of main lobe is $3.08 \mathrm{~dB}$, direction is 95 degrees and angular width is 86.2 degrees with side lobe level of $-2.3 \mathrm{~dB}$.

\section{B. Teflon}

With Teflon antenna showed good and satisfactory results showing multi-level response at different resonant frequencies.

TABLE IV. TEFLON SUBSTRATE RESULTS

\begin{tabular}{|l|l|l|l|}
\hline $\begin{array}{l}\text { Resonant } \\
\text { Frequency }\end{array}$ & Return Loss & Gain & Directivity \\
\hline 2.50 & $-25.3 \mathrm{~dB}$ & $2.97 \mathrm{~dB}$ & $4.23 \mathrm{dBi}$ \\
\hline 3.00 & $-35.7 \mathrm{~dB}$ & $4.11 \mathrm{~dB}$ & $5.39 \mathrm{dBi}$ \\
\hline 3.70 & $-11.48 \mathrm{~dB}$ & $4.49 \mathrm{~dB}$ & $6.49 \mathrm{dBi}$ \\
\hline 5.89 & $-13.32 \mathrm{~dB}$ & $0.0078 \mathrm{~dB}$ & $3.26 \mathrm{dBi}$ \\
\hline
\end{tabular}

The minimum return loss occurred at resonant frequency of $3.00 \mathrm{GHz}$ which was $-35.7 \mathrm{~dB}$ having gain of $4.11 \mathrm{~dB}$ and directivity of $5.39 \mathrm{dBi}$.

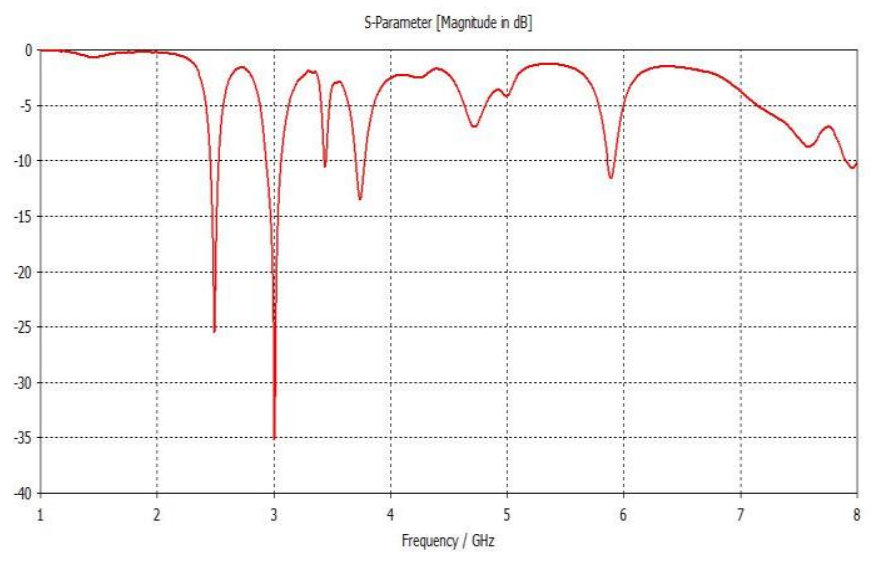

Fig. 8. Return Loss Plot of Teflon

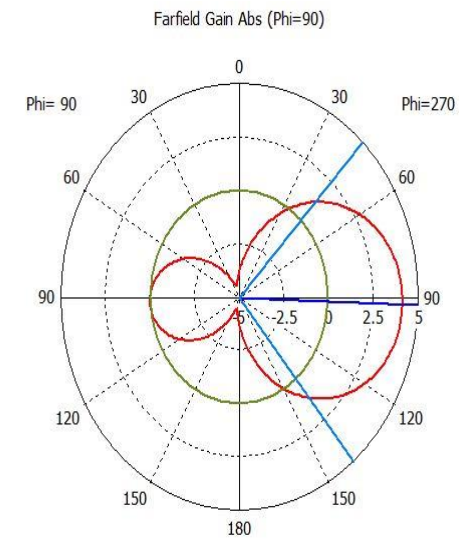

Theta / Degree vs. dB
— farfield $(f=3.00)[2]$
Frequency $=3$

Main lobe magnitude $=4.11 \mathrm{~dB}$

Main lobe direction $=92.0 \mathrm{deg}$. Angular width $(3 \mathrm{~dB})=97.0 \mathrm{deg}$. Side lobe level $=-4.1 \mathrm{~dB}$

Fig. 9. 1D plot of Gain at Resonant Frequency of $3.00 \mathrm{GHz}$

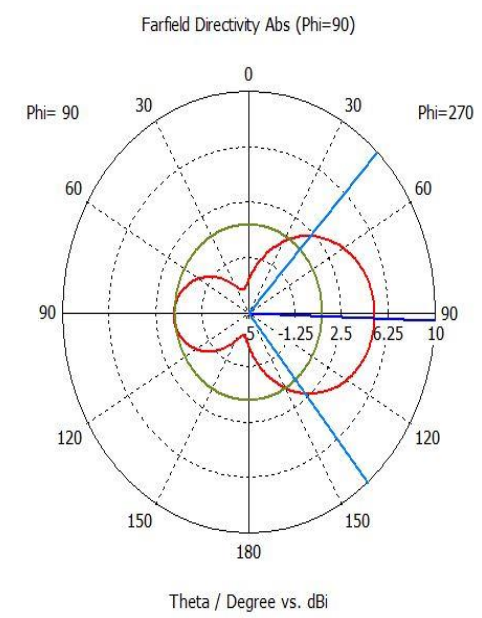

— farfield $(f=3.00)[2]$

Frequency $=3$

Main lobe magnitude $=5.13 \mathrm{dBi}$ Main lobe direction $=92.0 \mathrm{deg}$. Angular width $(3 \mathrm{~dB})=97.0 \mathrm{deg}$. Side lobe level $=-4.1 \mathrm{~dB}$

Fig. 10. 1D plot of Directivity at Resonant Frequency of 3.00 GHZ

In $3.00 \mathrm{GHz}$ the level of main lobe is $5.13 \mathrm{~dB}$, direction is 92 degrees and angular width is 97 degrees with side lobe level of $-4.1 \mathrm{~dB}$.

\section{Bakelite}

With Bakelite antenna showed quite good and satisfactory results by showing multi-level response at different resonant frequencies.

TABLE V. BAKELITE Substrate RESUlts

\begin{tabular}{|l|l|l|l|}
\hline $\begin{array}{l}\text { Resonant } \\
\text { Frequency }\end{array}$ & Return Loss & Gain & Directivity \\
\hline 2.30 & $-12 \mathrm{~dB}$ & $2.45 \mathrm{~dB}$ & $4.22 \mathrm{dBi}$ \\
\hline 2.73 & $-13 \mathrm{~dB}$ & $3.16 \mathrm{~dB}$ & $4.88 \mathrm{dBi}$ \\
\hline 3.45 & $-12.42 \mathrm{~dB}$ & $4.09 \mathrm{~dB}$ & $5.62 \mathrm{dBi}$ \\
\hline 6.58 & $-16 \mathrm{~dB}$ & $0.736 \mathrm{dBi}$ & $3.81 \mathrm{dBi}$ \\
\hline 7.74 & $-15 \mathrm{~dB}$ & $5.39 \mathrm{~dB}$ & $6.44 \mathrm{dBi}$ \\
\hline
\end{tabular}




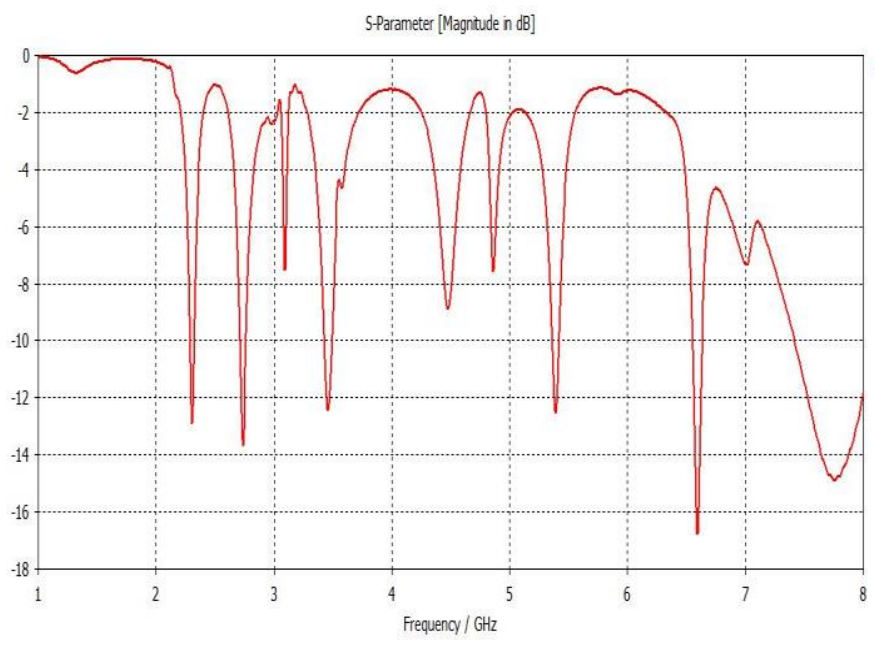

Fig. 11. Return loss of Bakelite

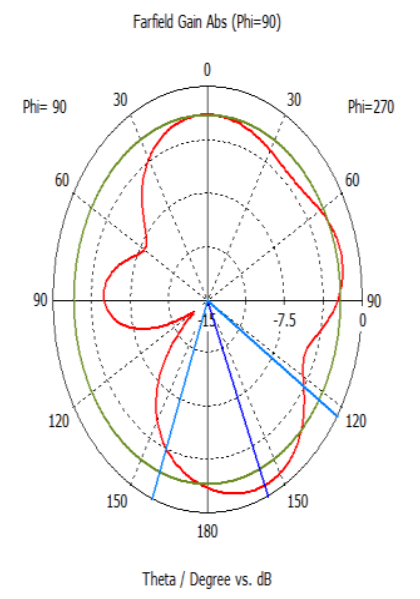

Frequency $=6.58$

Man lobe magntude $=-0.872 \mathrm{~dB}$ Man lobe direction $=157.0 \mathrm{deg}$. Anguar widh $(3 \mathrm{~dB})=78.2 \mathrm{deg}$.

Side lobe level $=-1.2 \mathrm{~dB}$

Fig. 12. 1D plot of Gain at Resonant Frequency of $6.58 \mathrm{GHZ}$

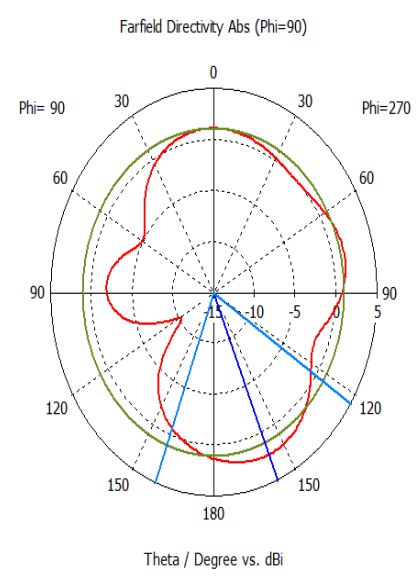

Frequency $=6.58$
Main lobe magnitude $=2.2 \mathrm{dBi}$
Main lobe drection $=157.0 \mathrm{deg}$.
Angular wdth $(3 \mathrm{~dB})=78.2 \mathrm{deg}$.
Side lobe evel $=-1.2 \mathrm{~dB}$

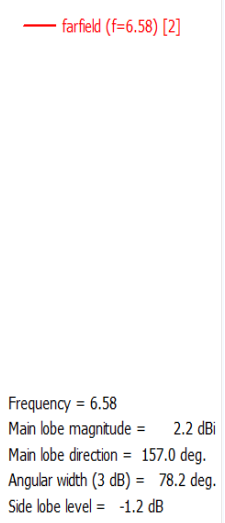

Fig. 13. 1D plot of Directivity at Resonant Frequency of $6.58 \mathrm{GHZ}$
In $6.58 \mathrm{GHz}$ the level of main lobe is $0.872 \mathrm{~dB}$, direction $157 \mathrm{deg}$, angular width is $78.2 \mathrm{deg}$ with Side lobe level of $1.2 \mathrm{~dB}$.

\section{Roggers5880}

With R05880 antenna showed quite good and satisfactory results by showing multi-level response at different resonant frequencies.

TABLE VI. Ro5880 SUbSTRATE RESUlts

\begin{tabular}{|l|l|l|l|}
\hline $\begin{array}{l}\text { Resonant } \\
\text { Frequency }\end{array}$ & Return Loss & Gain & Directivity \\
\hline 2.48 & $-22.7 \mathrm{~dB}$ & $2.95 \mathrm{~dB}$ & $4.21 \mathrm{dBi}$ \\
\hline 2.98 & $-27.7 \mathrm{~dB}$ & $4.05 \mathrm{~dB}$ & $5.11 \mathrm{dBi}$ \\
\hline
\end{tabular}

The minimum Return Loss occurred at resonant frequency of $2.98 \mathrm{GHz}$ which was $-27.7 \mathrm{~dB}$ having gain of $2.95 \mathrm{~dB}$ and directivity of $4.21 \mathrm{dBi}$.

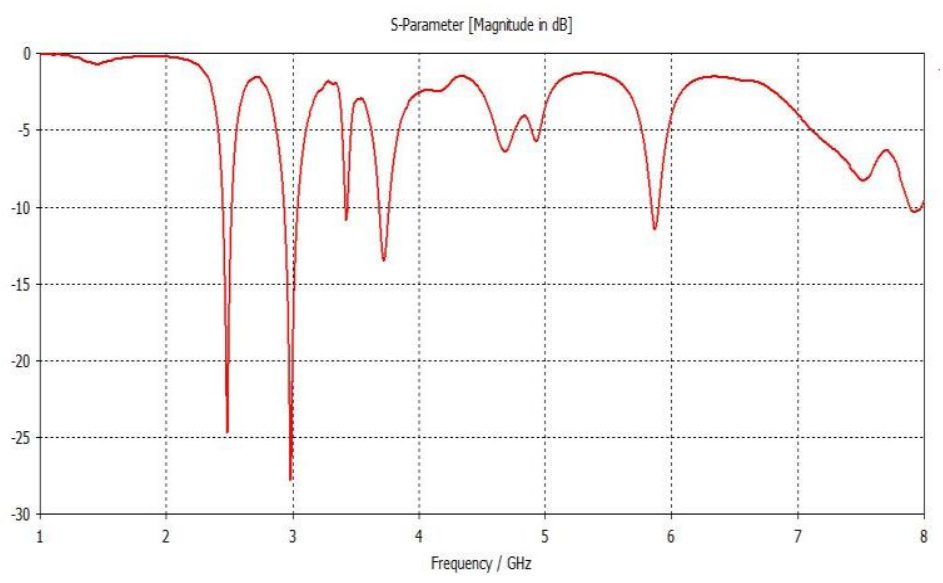

Fig. 14. Return loss of RO5880

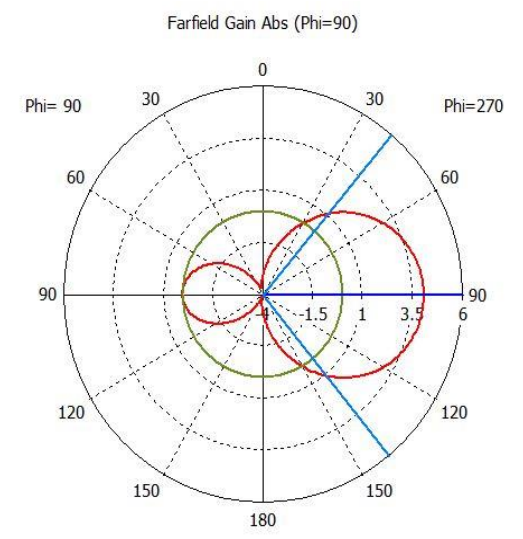

Theta / Degree vs. dB Side lobe level $=-4.0 \mathrm{~dB}$

Fig. 15. 1D plot of Gain at Resonant Frequency of $2.98 \mathrm{GHZ}$ 


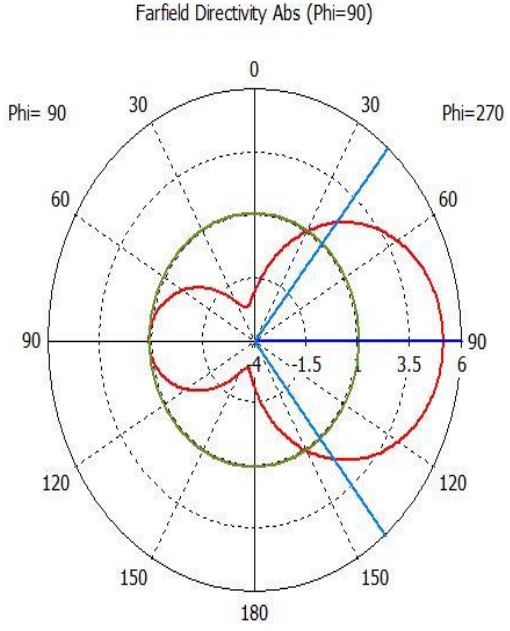

Theta / Degree vs. dBi
Frequency $=2.981$

Main lobe magnitude $=5.11 \mathrm{dBi}$ Main lobe direction $=90.0 \mathrm{deg}$. Angular width $(3 \mathrm{~dB})=100.5 \mathrm{deg}$. Side lobe level $=-4.0 \mathrm{~dB}$

Fig. 16. 1D plot of Directivity at Resonant Frequency of $2.98 \mathrm{GHz}$

In $2.981 \mathrm{GHz}$ the level of main lobe is $5.11 \mathrm{~dB}$, direction 90 deg with angular width of $100.5 \mathrm{deg}$ and Side lobe level of 4.0dB.

\section{CONCLUSION}

This paper presents a novel design of miniaturized multiband patch antenna using different substrates frequently used in patch antennas. The proposed miniaturized multiband patch antenna contains 2 substrates where one substrate is FR4 (fixed and lossy) and the other substrates are changed to observe gain, directivity and return loss. In this paper coaxial probe feeding technique is also used. The proposed antenna can be used for various S-band and C-band applications such as mobile communication, WIMAX, WLAN and Vehicular communication etc.

\section{REFERENCES}

[1] Rahamdani and A. Munir, "Microstrip patch antenna minaturaization using artifical magnetic conductor" in Telecommunication Systems, Services and Applications (TSSA), $20116^{\text {th }}$ International conference on 2011,pp.219-223

[2] M. M. Bait-Suwailam and H. M. Al-Rizzo, "Size reduction of microstrip patch antennas using slotted Complementary Split-Ring Resonators," in Technological Advances in Electrical, Electronics and Computer Engineering (TAEECE), 2013 International Conference on, 2013, pp.528-531,

[3] S. S. Gaikwad, et al., "Size miniaturized fractal antenna for $2.5 \mathrm{GHz}$ application," in Electrical, Electronics and Computer Science (SCEECS), 2012 IEEE Students' Conference on, 2012, pp. 1-4.R. Nicole, "Title of paper with only first word capitalized," J. Name Stand. Abbrev., in press.

[4] C. A. Balanis, Antenna Theory: Analysis and Design, $3^{\text {rd }}$ ed.NewYork,NY,USA:Wiley,2005.

[5] Abbaspour, M. and H. R. Hassani, "Wideband star shaped microstrip p atch antenna," Progress In Electromagnetics Research Letters, Vol. 1, pp.61-68, 2008.

[6] Ansari, J. A. and R. B. Ram, "Broadband stacked U-slot microstrip p atch antenna," Progress In Electromagnetics Research Letters, Vol. 4, pp.17-24, 2008.

[7] M. M. Bait-Suwailam and H. M. Al-Rizzo, "Size reduction of microstrip patch antennas using slotted Complementary Split-Ring Resonators," in Technological Advances in Electrical, Electronics and Computer Engineering (TAEECE), 2013 International Conference on, 2013, pp. 528-531.

[8] H. Oraizi and S. Hedayati, "Miniaturization of Microstrip Antennas by the Novel Application of the Giuseppe Peano Fractal Geometries," Antennas and Propagation, IEEE Transactions on, vol. 60, pp. 3559$3567,2012$.

[9] John D Kraus ,Ronald J Marhafka and Ahmad S khan“Antenna and Wave Prop agation" Text Book.

[10] Y. Cheng-Chi, et al., "A compact antenna based on metamaterial for WiMAX," in Microwave Conference, 2008. APMC 2008. Asia-Pacific, 2008, pp. 1-4.

[11] D. Sievenpiper, H. P. Hsu, J. Schaffner, G. Tangonan, R. Garcia, and S. Ontiveros, "Low profile, four sector diversity antenna on high impedance ground plane," Electron. Lett. vol. 36, pp. 1343 1345, 2000.

[12] Zhang, X. Yang, "Study of a slit cut on a microstrip antenna and its applications," Microwave and Optical Technology Letters, vol.18, no.4, pp.297- 300, 1998. 